\title{
POVOS TRADICIONAIS CAIÇARAS, EDUCAÇÃO ESCOLAR E JUSTIÇA AMBIENTAL NA PENÍNSULA DA JUATINGA, PARATY-RJ
}

\author{
Vanessa Marcondes de Souza ${ }^{1}$ e Carlos Frederico Bernardo Loureiro ${ }^{2}$
}

\section{RESUMO}

Diante do enfrentamento de diversos processos de expropriação, os povos tradicionais caiçaras da Península da Juatinga, Paraty-RJ, passaram a demandar o acesso à educação escolar. Este artigo tem como objetivo discutir os elementos que em conjunto produzem situações de injustiça ambiental e levam a expropriações desses povos, tendo como foco o papel da educação escolar dentro deste processo. A luta pela educação escolar desses povos, como parte constitutiva de suas lutas pelo direito de reproduzirem seus modos de vida, está inserida no contexto de resistência e enfrentamento à dominação social e à injustiça ambiental.

Palavras-chaves: educação escolar; justiça ambiental; expropriação.

\begin{abstract}
Giving the confrontation of various expropriation processes, the traditional caiçaras peoples of the Juatinga peninsula, Paraty-RJ, began to demand access to school education. This article aims to discuss the elements that together produce situations of environmental injustice and lead to the expropriation of these peoples, focusing on the role of school education in this process. The struggle for the education of these peoples, as a constituent part of their struggle for the right to reproduce their ways of life, is inserted in the context of resistance and confrontation with social domination and environmental injustice.
\end{abstract}

Keywords: school education; environmental justice; expropriation.

\footnotetext{
${ }^{1}$ Licenciada e Bacharel em Ciências Biológicas pela Universidade Federal Fluminense (UFF). Mestre em Ciência Ambiental (PGCA - UFF). Doutora em Psicossociologia de Comunidades e Ecologia Social pelo Programa EICOS - UFRJ. Participa do laboratório de investigação em Educação, Ambiente e Sociedade (Lieas), do Grupo Interinstitucional de Estudos sobre Estado, Poder e Educação (Giepe) e do coletivo de educadores que apoiam o Fórum de comunidades Tradicionais Angra, Paraty e Ubatuba.

${ }^{2}$ Biólogo. Mestre em Educação. Doutor em Serviço Social. Professor no programas de PósGraduação em Educação (UFRJ). Pesquisador CNPq. Coordenador do Laboratório de Investigações em Educação, Ambiente e Sociedade (Lieas).
} 


\section{Introdução}

A Península da Juatinga, região isolada geograficamente e bastante conservada no município de Paraty-RJ, abriga em torno de 20 comunidades tradicionais que se autodenominam como caiçaras. De acordo com Cruz (2012), o termo povos e comunidades tradicionais é uma categoria de análise e conceito antropológico que busca nomear e caracterizar diversas comunidades rurais com fortes laços territoriais constituídos sobre um trabalho não-alienado e coletivo e com traços de identidade cultural bem definidos. Mas, segundo o mesmo autor, também é uma categoria de ação política, como identidade sociopolítica mobilizadora de lutas por direitos em uma sociedade que destrói seus modos de vida. Em muitos desses grupos, o sistema de produção em que estão inseridos não é marcado pela rápida acumulação de capital (PORTOGONÇALVES, 2006), se contrapondo às visões de mundo que mercantilizam a vida e dicotomizam os seres humanos e a natureza (LOUREIRO, 2012).

Apesar das suas atividades tradicionais estarem intimamente relacionadas à biodiversidade local, da qual dependem para a reprodução material e cultural, esses povos não estão isolados e livres de influências das relações socioeconômicas da cultura hegemônica capitalista, estando em diferentes graus de contato e dependência dos centros urbanos. É preciso compreender que a expansão das relações sociais capitalistas age sobre os territórios tradicionais, impondo regras e, com isso, trazendo novas necessidades e novas estratégias de resistência. A demanda por educação escolar é uma delas, tornando-se necessária como condição objetiva de existência desses povos (SOUZA e LOUREIRO, 2015).

Desta forma, este artigo tem como objetivo discutir os elementos que em conjunto produzem situações de injustiça ambiental e levam a expropriações dos povos tradicionais caiçaras da Península da Juatinga, tendo como foco o papel da educação escolar dentro deste processo. A partir do campo de estudo da ecologia política e da educação ambiental (EA) crítica traremos parte dos resultados da pesquisa de doutorado finalizada em 2017 (SOUZA, 2017), relativos à revisão bibliográfica e às entrevistas realizadas com caiçaras ${ }^{3}$.

\footnotetext{
${ }^{3}$ Os caiçaras entrevistados foram identificados como "morador" seguido por uma numeração. Entretanto, foram mantidos os nomes das lideranças entrevistadas entendendo que estes são sujeitos políticos reconhecidos por suas lutas em busca de seus direitos.
} 
A Ecologia Política foca a sua atenção nos modos pelos quais diferentes agentes disputam e compartilham os recursos naturais, nos processos econômicos, culturais e políticos-institucionais, nos quais a sociedade se organiza e se estrutura (LOUREIRO, 2012). E a EA, fundamentada na teoria social crítica marxista, trabalha:

\begin{abstract}
na explicitação dos mecanismos de produção (pela expropriação do trabalho e uso intensivo e expansivo da natureza) e reprodução (pela dominação de Estado, hegemonia ideológica e opressão social) do capitalismo, na postura teórico-prática transformadora, no posicionamento político comprometido com as lutas populares por emancipação (LOUREIRO, 2015, p.163).
\end{abstract}

Partindo deste referencial teórico, a crítica ao modo de produção capitalista se faz presente, principalmente, por compreender que sua dinâmica de produção se baseia na acumulação permanente do capital e da intensificação da expropriação da natureza e dos seres humanos.

\title{
Expropriação dos territórios tradicionais
}

As expropriações remetem ao processo histórico denominado por Marx (2015) de acumulação primitiva ou originária, no qual houve a separação do produtor do seu meio de produção, levando a grandes concentrações de recursos nas mãos de poucos e a formação de um grande contingente de indivíduos despossuídos dos seus meios de produção, passando este a serem detentores apenas de sua força de trabalho para garantirem a sua própria existência. Fontes (2010, p.45) explica que "as expropriações constituem um processo permanente, condição da constituição e expansão da base social capitalista e que, longe de se estabilizar, aprofunda-se e generaliza-se".

Embora hoje existam leis que reconheçam os territórios tradicionais, estes são tratados historicamente como obstáculo para a expansão econômica ou como algo a ser apropriado e reorganizado segundo os interesses hegemônicos (HARVEY, 2011). Com isso, as populações tradicionais estão em permanentes conflitos com as forças do capital para uso e a apropriação dos recursos naturais, podendo estes ser considerados como conflitos ambientais (MARTINEZ-ALIER, 2011), que segundo Acselrad (2004), são aqueles que envolvem:

grupos sociais com modos diferenciados de apropriação, uso e significação do território, tendo origem quando pelo menos um dos 
grupos tem a continuidade das formas sociais de apropriação do meio que desenvolvem ameaçada por impactos indesejáveis (...) decorrentes do exercício das práticas de outros grupos (ACSELRAD, 2004, p.26).

O grande marco da história recente do município de Paraty, que representa o início das expropriações dos territórios tradicionais caiçaras, é a construção da BR-101 (trecho Rio-Santos) nas décadas de 1960 e 1970. Apesar da estrada em si não ter alcançado a Península da Juatinga, que se mantém sem acesso rodoviário, trouxe grandes transformações socioeconômicas ao possibilitar a expansão do modo de vida e produção capitalista na região, trazendo a especulação imobiliária, a exploração turística, as proteções ambientais ${ }^{4}$, além de perspectivas para novos investimentos de grupos empresariais.

Atualmente, são diversos os projetos de grande infraestrutura instalados e atuando na região da Costa Verde ${ }^{5}$ : a operação e a expansão das instalações do Estaleiro Brasfels, em Angra dos Reis; a operação e expansão do terminal Portuário de Angra dos Reis; a operação das Usinas Nucleares Angra 1 e 2 e a construção da Usina Nuclear Angra 3; a operação e expansão do Terminal da Baía da Ilha Grande; e a exploração e produção do Pré-Sal na Bacia de Santos, que impacta por utilizar os terminais e portos das cidades vizinhas, aumentando o tráfego de embarcações na área e o volume de plataformas de petróleo.

Como resultado deste processo em Paraty, não só o modo de vida tradicional foi ficando inviável em sua reprodução social como muitos caiçaras foram expulsos de seus territórios para as periferias mediante estratégias de

\footnotetext{
${ }^{4}$ Como reação aos impactos da expansão urbana na região, a política de diversos governos para a proteção dos ambientes naturais, ainda bem conservados em Paraty, foi a demarcação de Unidades de Conservação (UCs). Foram criadas duas UCs na Península da Juatinga: a Área de Proteção Ambiental (APA) de Cairuçu em 1983, sob a administração do Instituto Chico Mendes de Conservação da Biodiversidade (ICMBio), e a Reserva Ecológica Estadual da Juatinga (REEJ) em 1992, de responsabilidade do Instituto Estadual do Ambiente (INEA). Os modelos de gestão ambiental não se aliaram aos caiçaras para a conservação ambiental e também não tiveram sucesso em combater a especulação imobiliária e as privatizações, impondo aos caiçaras revisões às suas práticas tradicionais e necessidade de compreensão sobre as questões ambientais.

${ }^{5}$ A região da Costa Verde refere-se aos municípios de Mangaratiba, Angra dos Reis e Paraty no litoral sul fluminense.
} 
convencimento discursivo e/ou uso de força ${ }^{6}$. As expropriações sobre os territórios tradicionais vão incidir em:

direitos tradicionais, como uso de terras comunais, direitos consuetudinários, relação familiar mais extensa e entreajuda local, conhecimento sobre plantas e ervas locais, dentre outros aspectos, e envolve profundas transformações culturais, ideológicas e políticas (FONTES, 2010, p.51).

Assim, os territórios tradicionais foram e ainda são convertidos em terras mercantilizadas ou mercantilizáveis e os caiçaras que foram expropriados de seus meios de produção e dos seus territórios, dentro deste contexto, servem de mão-de-obra abundante e barata para as classes dominantes, que continuam a enriquecer e a comandar a cidade.

As relações sociais capitalistas ao se expandirem sobre os territórios tradicionais impõem, então, regras e trazem novas necessidades. É nesse contexto de maior interação dos povos caiçaras com a sociedade urbanoindustrial que a educação escolar passou a ser demandada e a sua negação ou a forma como vem sendo ofertada em algumas localidades tem contribuído como parte dos processos de expropriações.

\section{A educação tradicional caiçara}

A educação, entendida sob o ponto de vista ontológico, é uma exigência de toda e qualquer sociedade, uma vez que ela é constitutiva do ser social, da vida social (LOUREIRO e GARAJAU, 2016).

Não há sociedade sem educação, no sentido de que não há vida social sem que o que a humanidade produziu (instrumentos, tecnologia, ciência, arte, condutas, costumes, valores, conhecimentos vários, ou seja, cultura) seja transmitido, reproduzido, ampliado, socializado e transformado. Compreender o mundo, ter consciência dele, interpretá-lo, "ser mundo", fazer juízo de valor e estabelecer códigos linguísticos são acontecimentos que se efetivam somente em sociedade (Ibid., p.44).

No processo histórico de humanização do homem, a educação era realizada em decorrência da produção material e da apropriação coletiva dos meios (SAVIANI, 2014), ou seja, pelo trabalho, não existindo outras formas de educação que não a do simples convívio. Era trabalhando a terra e garantindo a própria sobrevivência que o povo se educava (Ibid.). A modalidade principal de educação era, então, o trabalho.

\footnotetext{
${ }^{6}$ Sobre os conflitos envolvendo os povos caiçaras e grileiros na região da Costa Verde, ver o livro "O genocídio Caiçara" de Siqueira (1984), as dissertações de mestrado de Cavalieri (2003) e Monge (2012) e o relatório "Conflitos por terra e repressão no campo na região da Costa Verde, Litoral Sul Fluminense" (FEITOSA e SILVA, 2015).
} 
Os homens aprendiam a produzir sua existência no próprio ato de produzi-la. Eles aprendiam a trabalhar, trabalhando. Lidando com a natureza, relacionando-se uns com os outros, os homens se educavam e educavam as novas gerações. A produção da existência implica o desenvolvimento de formas e conteúdos cuja validade é estabelecida pela experiência, o que configura um verdadeiro processo de aprendizagem. Assim, enquanto os elementos não validados pela experiência são afastados, aqueles cuja eficácia a experiência corrobora necessitam ser preservados e transmitidos às novas gerações no interesse da continuidade da espécie (SAVIANI, 2014, p.25).

Os povos caiçaras que, até algumas décadas atrás, pouco se relacionavam com a sociedade dominante, se educam em comunidade através da realização dos seus trabalhos, suas práticas tradicionais. As crianças participam na realização das atividades diárias, brincando ao redor das cordas, redes e peixes, carregando materiais leves, ajudando a puxar redes de pesca ou separando os peixes, etc. Nessa ajuda, que se mistura com brincadeiras, vão aprendendo os trabalhos da cultura caiçaras e assim vão tornando-se caiçaras que conhecem sobre a dinâmica do mar e da mata, sabem pescar, caçar, roçar, fazer canoa, cestaria, entre outras atividades que, ao longo do tempo, vão se incorporando à organização sociocultural desses povos. Nesse processo educativo tradicional, não há necessidade da escolarização conforme explicam os caiçaras:

A minha escola era trabalhar e pelo trabalho eu aprendi essas coisas toda. Se tivesse uma escola, do jeito que eu queria aprender eu acho que eu também sabia ler e escrever muito bonitinho (...), era até professor, com diploma na mão porque tinha vontade de aprender. Mas, na parte do trabalho aprendi tudo e passei pros filho, os filhos não tiveram escola também, mas aprenderam a trabalhar (Seu Maneco).

O caiçara aprende muito a lidar com a terra, com o mar, é a vivencia que se tem no dia a dia, por mais que você não vai pro mar todo dia, mas você aprende com o seu pai, seus irmãos, seus avós. (...) Você pode pegar qualquer criança que mora na costeira, ela sabe tudo, porque ela vive o dia a dia. A mesma coisa, você aprende com seu pai e sua mãe a ter o caráter dele, a educação que ele te deu, nas comunidades você aprende com todo mundo, com a comunidade a ir no cerco $^{7}$, a saber a lua, a saber o vento, então essa vivencia mesmo (Leila).

Nobre (2016), ao trabalhar com a infância indígena guarani, afirma que "o lugar de produção de sentidos para essa infância tem sido a comunidade educativa, com seus modelos de imitações da vida adulta e suas brincadeiras e jogos infantis". Acreditamos que o mesmo pode ser afirmado sobre a infância caiçara. Identificamos que suas brincadeiras envolvem os elementos naturais

\footnotetext{
${ }^{7}$ Arte de pesca característica da região que envolve toda a família.
} 
ao seu redor, mas também os instrumentos de trabalho caiçara e as próprias atividades de trabalho. É bastante comum os mais velhos fazerem para as crianças remos de tamanho menores, canoas e barcos pequenos que se transformam em brinquedos e brincadeiras.

A educação caiçara, então, tem o trabalho como princípio educativo. Os caiçaras ao exercerem seus trabalhos, suas práticas tradicionais diárias, na relação com a natureza e em comunidade, se educam e, assim, se formam enquanto caiçaras, constroem suas relações com a natureza e com o território.

A partir do momento em que o modo de vida urbano-industrial, as relações econômicas mercantis e o cumprimento de obrigações perante 0 poder público começam a influir nos modos de vidas dessas populações criamse novas necessidades e muda-se o entendimento e 0 significado de educação. O oferecimento da educação escolar nas próprias comunidades caiçaras começa a ser reivindicado pelos povos tradicionais.

\title{
Demanda por educação escolar
}

A educação escolar é considerada como primordial nas sociedades contemporâneas, pois, conforme explica Saviani (2011), esta, ao longo da história, se transformou na forma principal e dominante de educação:

\begin{abstract}
Esta passagem da escola à forma dominante de educação coincide com a etapa histórica em que as relações sociais passaram a prevalecer sobre as naturais, estabelecendo-se o primado do mundo da cultura (o mundo produzido pelo homem) sobre o mundo da natureza. Em consequência, o saber metódico, sistemático, científico, elaborado, passa a predominar sobre o saber espontâneo, "natural", assistemático, resultando daí que a especificidade da educação passa a ser determinada pela forma escolar. A etapa histórica em referência - que ainda não se esgotou - corresponde ao surgimento e desenvolvimento da sociedade capitalista (SAVIANI, 2011, p.7).
\end{abstract}

Com isso, o conhecimento intelectual se tornou uma exigência nas sociedades contemporâneas e a educação escolar passou a ser a forma socialmente dominante de educação.

Os caiçaras, historicamente, são descritos como pertencentes a comunidades cujos conhecimentos são transmitidos através da oralidade, não havendo o uso da escrita nem o reconhecimento sobre o alfabeto. Entretanto, o histórico de assinaturas de documentos pelos caiçaras que não sabiam ler e escrever e que os levou a entregar suas terras para os grileiros em Paraty $^{8}$ é

\footnotetext{
${ }^{8}$ Sobre esta questão ver as dissertações de Cavalieri (2003) e Mendonça (2010).
} 
referência para alguns caiçaras e justifica a preocupação dos mesmos em adquirir este conhecimento, conforme explicam abaixo.

Porque os mais velhos não tiveram oportunidade de estudar. Então, tudo que eles sofreram antigamente, principalmente com os grileiros, foi muito também por conta também da falta de escola por eles não saberem ler e escrever e sair assinando documento, acreditando na pessoa que está vindo de fora. Eu acho que a escola trás um pouco desse empoderamento da comunidade, eles só de saber ler e escrever parece que já muda completamente. Não é que vai fazer a pessoa mais sábia ou não. Não é. Mas, ela dá uma segurança pra essa pessoa (...). Se alguém chegar com um papel ali na tua mão e falar que você tem que assinar (...) é uma segurança (Marcela).

Ajuda porque a gente passa a ver de outra forma também, se estuda. Por isso, tem o estudo para você poder ler alguma coisa, entender, quando você começa ler. Se você não sabe ler, você vai sempre vai tá ouvindo o que os outros falam. Mas, se os outros falam e você quer ter certeza, você vai ver, sabe? Então, você começa porque não tá só falando, você também tá lendo. Por isso é importante (Ticote).

Embora, haja esse marco histórico que causa preocupação nos caiçaras de vir a se repetir, diversos são os problemas enfrentados no cotidiano dos caiçaras decorrentes da falta de acesso a escolarização. Um dos problemas está na exigência da Capitania dos Portos (órgão vinculado a Marinha responsável pela segurança do tráfego aquaviário) por algum grau de escolarização para a realização de um curso teórico, necessário para a obtenção da habilitação de Pescador Profissional (POP) e para a obtenção da habilitação de Marinheiro Auxiliar de Convés (MAC), que permite a condução de embarcação com passageiros, que seria o caso quando os caiçaras trabalham com o turismo (MARINHA, 2017).

Entretanto, historicamente, o oferecimento da educação escolar nessas regiões tem se dado de forma bastante precária, não garantindo a continuidade do processo educativo, seja por não haver escolas em algumas localidades, seja pelas condições precárias de trabalho em outras localidades que desestimula a ida e permanência dos profissionais da educação nessas localidades.

A maioria das escolas de Paraty está localizada na área rural. Só na rede municipal, que conta com 33 escolas, 26 estão localizadas na zona rural, sendo 9 delas na região costeira ${ }^{9}$. A maioria das escolas localizadas na zona rural

\footnotetext{
${ }^{9}$ Em Paraty, a palavra costeira é utilizada para se referir às regiões aonde só se chegam de barco, como as ilhas e as comunidades da Península da Juatinga, que não possuem acesso por estradas.
} 
oferece somente o ensino fundamental I (1ำ ao 5ano) e até 2015, somente três escolas da rede municipal e três da rede estadual ofereciam o ensino fundamental II (6ำ ao $9^{\circ}$ ano $)^{10}$. Assim, não existem muitas opções para os moradores da zona rural que desejam ter acesso à educação escolar e concluir os estudos.

$\mathrm{Na}$ Península da Juatinga existem cinco escolas em funcionamento que oferecem o ensino fundamental I. Estas estão localizadas nas comunidades de mais fácil acesso e com maior número de habitantes, Sono, Ponta Negra, Ponta da Juatinga, Pouso e Calhaus. Já nas consideradas mais isoladas e com menor número de habitantes não existem escolas. Para os moradores da Península da Juatinga, as opções são: 1) o deslocamento diário via trilha ou mar para uma região com escola, o que quase sempre é inviável, por questões geográficas e naturais da região; 2) a mudança temporária ou permanente para uma região com escola, o que faz com que os caiçaras tenham que sair de suas comunidades, inviabilizando muitos dos seus trabalhos tradicionais e acarretando mudanças na dinâmica familiar e nos modos de vida caiçaras.

Dados sobre o nível de escolaridade, coletados pela Fundação Instituto de Pesca do Estado do Rio de Janeiro (FIPERJ) em mais de 327 localidades de pesca entre as cidades de Cabo Frio e Paraty, demonstram que mais de $60 \%$ dos pescadores do Estado do Rio de Janeiro não possui o ensino fundamental completo e que $3 \%$ não possui grau de escolaridade algum (FIPERJ, 2015). Da mesma forma, na Península da Juatinga, grande parte dos caiçaras é considerada analfabeta ou estudou somente até a antiga $4^{a}$ série, pois em suas comunidades não existe o ensino fundamental completo. Com isso, a exigência dos cursos pela Capitania dos Portos para a obtenção dos documentos de habilitação faz com que a maioria dos caiçaras trabalhe na ilegalidade. Até mesmo para adquirir um motor ou uma embarcação é necessário saber assinar o nome.

\footnotetext{
${ }^{10}$ Na rede municipal são: a E.M. Professora Pequenina Calixto, localizada no centro urbano de Paraty; a E.M. Cilencina Rubem de Oliveira Mello, localizada na zona rural, no bairro Barra Grande e a E.M. Sergio Mota, localizada no bairro Pantanal, considerado zona rural, apesar de já estar bastante urbanizado. Já na rede estadual, são: o C.E. Almirante Álvaro Alberto, localizado no bairro Mambucaba, no distrito de Tarituba; o C.E. Engenheiro Mauro Moura Brasil do Amaral (CEMBRA) e o CIEP Dom Pedro Alcântara Bragança, localizados na área urbana de Paraty.
} 
Nunca teve toda nossa infância, agora já adulto, até mesmo meus avós desde que nasci nunca teve escola ali. Nunca a gente aprendeu ler e escrever. (...) As nossas crianças também estão crescendo e sem estudo. $\mathrm{E}$ hoje a gente quer muito que isso aconteça na vida das crianças ali. Até de nós mesmo adulto que a gente tá tendo uns grandes pobremas aí que não podemos nem dirigir a embarcação nossa porque não temos o direito de tirar uma habilitação porque não sabemos ler e nem escrever. Então, tá difícil pra gente (morador 04).

Uns tempos desse, eu comprei um motor lá em Caraguá. O cara pegou o documento, certo e tal. O outro teve que assinar no meu lugar porque eu não sabia ler e escrever, não aceitava. Não aceitava. Quem era o culpado deu não saber lê e escrevê? Não era o governador, o prefeito da época que não quis botar escola? Era eu que era o culpado? Não, não tinha escola! Eu fiquei chateado com aquilo e botei meu filho pra assinar, o motô é dele, não é meu (Seu Maneco).

Assim, embora os caiçaras trabalhem desde crianças com a pesca e tenham conhecimentos práticos sobre o vento, mar, as correntes e as embarcações, somente com esses documentos podem trabalhar legalmente. Os caiçaras ao invés de questionar esse regramento, criado descontextualizado da realidade e desrespeitando sua organização social, passam, então, a se adequar a essa exigência, demandando a escolarização. Desta forma, conforme explicam Loureiro e Franco (2014), o conhecimento torna-se um mecanismo de opressão de uma classe sobre a outra. E neste caso, o saber prático e tradicional da organização social caiçara é desconsiderado, pois se priorizam os conhecimentos teóricos hegemônicos, legitimados pela existência de um certificado de escolarização. Assim, estabelecem-se hierarquias entre os conhecimentos e os grupos sociais, ao mesmo tempo em que se constroem preconceitos e mecanismos de dominação.

A falta de reconhecimento por parte da sociedade de que esses grupos são também detentores de conhecimentos, além de trazer problemas práticos para a vida dos caiçaras, como no caso da obtenção das habilitações, também influência diretamente no desenvolvimento pessoal e coletivo da comunidade. É possível identificar uma baixa autoestima dos indivíduos, muitos se sentem inferiorizados e têm vergonha do jeito de ser e de falar.

Eu sinto muita dificuldade. Eu, às vezes, vou conversar, eu fico com vergonha de fala errado, de falar palavras. E, às vezes, eu vou conversar com um turista e eu vejo que ele ri, tipo não sei se ele tá rindo de mim ou tá rindo do jeito de falar, eu vejo que ele dá risada. Ai, me deixa um pouco retraída que eu não sei do que ele tá rindo. (...) (A escola) eu acho que ela ensina melhor, ela capacita melhor a gente pra 
essas coisas. Eu sinto muita falta de ter estudado só até a quarta série, muita falta mesmo (moradora 06).

Assim, os caiçaras acreditam que o acesso à escola pode trazer os ensinamentos sobre como se comportar da forma socialmente aceita pela cultura hegemônica, o que não deixa de ser verdade, pois como explicam Martins et al. (2014):

\begin{abstract}
a instituição escolar assumiu a função de viabilizar a formação intelectual e moral conforme as referências de certo tempo histórico. Sua generalização e legitimação correspondem ao reconhecimento, ainda que contraditório, de que para estar no mundo e viver coletivamente se tornou indispensável certo domínio de códigos culturais (MARTINS et al., 2014, p.263).
\end{abstract}

A exigência, então, do domínio da leitura e escrita para realizar atividades comuns aos caiçaras é uma das razões pelas quais a escola passa a ser uma demanda entre eles. As transformações que vêm ocorrendo trazem preocupações, principalmente, quanto ao futuro das gerações mais novas.

Eu tive na escola, fui até a quarta série. Mas tem meus sobrinhos, que é sobrinhos do meu esposo, minha filha. $E$ eu não quero que eles crescem cidadão desconhecido pela sociedade, quero que eles tenham grandes objetivos alcançar (moradora 02).

A dificuldade que sempre teve aqui foi com o estudo mesmo. Eu mesmo só estudei até a quarta séria e eu acho um absurdo porque a gente aqui é desprezado. É como se a gente não existisse, fosse um povo abandonado. Eu acho difícil eu ter estudado até a quarta série. Eu não quero isso pros meus filhos. (...) Eu acho um absurdo não ter um estudo mais aprofundado pra eles, ne? É complicado porque hoje em dia tudo gira em torno do estudo, ne? (...) Apesar da gente viver no lugar que a gente vive, mas a gente tem que se preocupar com estudo. A gente não tem que viver só pensando que a gente vai viver no nosso mundinho. E se daqui mais um tempo começa a crescer? E ai? Como é que vai ser sem estudo? Eu me preocupo muito com isso (moradora 06).

As falas dos pais preocupados com o futuro dos filhos demonstram que os mesmos têm consciência de que a falta de acesso à educação escolar faz com que os caiçaras estejam excluídos dessa sociedade, o que Fontes (2010) chamaria de exclusão interna, uma vez que não existe a possibilidade de estar fora das relações hegemônicas estabelecidas. A necessidade por escolas para continuar existindo ainda que na sua forma tradicional representa o que a autora chamaria de inclusão forçada nesta sociedade.

Além disso, conselho tutelar também pressiona os caiçaras para matricularem seus filhos nas regiões que possuem escolas. Essa pressão tem 
importante papel na mudança da estrutura comunitária, pois gera medo e insegurança em relação ao futuro familiar, o que faz com que muitos pensem em se mudar para outras localidades com escola, uma vez que o deslocamento diário entre as comunidades da Península da Juatinga ou delas para Paraty, proposto como solução por esse órgão, é praticamente inviável.

A gente fica pensando, a gente fica entre a cruz e a espada. A gente não sabe se dá um estudo ou se cuida da vida deles. Porque imagina você tira um filho daqui por causa do estudo, você perde seu filho pra droga, pro mundo do crime. Então, você fica sem saber o que fazer. (...) Os que sai, não é todos, mas a maioria se perdem, entendeu? Então, a gente tem que conservar eles aqui mesmo, ensinar direito, sabe? Dar uma boa educação, ensinar, valorizar (moradora 06).

Aqui é melhor de se viver que na cidade porque aqui tem família e também tem o peixe do mar que é mais fácil do que tá sempre com dinheiro pra poder comprar as coisas no mercado. A gente, eu falo que é mais fácil porque em Paraty você compra o arroz e o feijão, você precisa ter dinheiro para a carne, pra comprar alguma coisa pra ser a mistura do seu alimento. E já aqui, a gente vai ali, joga uma rede, pega um anzol, pesca e também o pessoal que tem cerco, que tem rede no mar, eles dão, ajudam também é mais fácil. É mais fácil de se viver na roça, na costeira do que na cidade. (...) E pra gente viver em Paraty não dá, porque pra continuar a escola delas e ter que sair daqui não dá porque eu não tenho condições de pagar aluguel e não vou deixar eles na mão da família deles na parte do pai porque eu sei que vão ser, não vão ficar de olho neles. Então, eles podem se envolver com um monte de coisa que não é certo (moradora 07).

Assim, a matrícula escolar, cobrada pelo conselho tutelar, nem sempre se efetiva. Aqueles que por diversos motivos escolhem permanecer nos seus territórios, onde os filhos ficam sem escolarização sofrem a penalização da retirada do auxílio financeiro do programa Bolsa Família ${ }^{11}$, pois este está atrelado à frequência escolar. Com isso, tem-se uma política de dupla penalização sobre esses grupos sociais. Primeiro com a ausência de escolas e o não oferecimento de qualquer alternativa viável para a resolução da problemática e segundo com a retirada do auxílio financeiro governamental, que complementa as rendas familiares, principalmente em épocas em que a pesca é impossibilitada pelas condições adversas do mar e na época de baixa temporada, deixando essas comunidades em situação ainda mais vulnerável.

${ }^{11}$ O Programa Bolsa Família, criado em 2004, é um programa do governo federal destinado às ações de transferência de renda a unidades familiares que se encontram em situação de pobreza e extrema pobreza. A concessão dos benefícios depende do cumprimento de condicionalidades, entre elas à frequência escolar de $85 \%$ em estabelecimento de ensino regular (BRASIL, 2004). 
Diante dessas medidas coercitivas como penalização pela ausência da carteira de pesca e a retirada do auxílio governamental, muitas famílias se mudam para outras comunidades ou para o centro urbano de Paraty, onde, quase sempre, passam a viver nos bairros periféricos da cidade, principalmente nas favelas. Assim, algumas de suas práticas tradicionais precisaram ser abandonadas, pois na cidade não possuem acesso aos recursos naturais fundamentais para o exercício de seus trabalhos.

A gente plantava, eu já colhi doze quilos de feijão. A gente tinha nossa horta, sabe? Com várias coisas, cenoura, couve flor. Então, a gente não tem mais isso. A gente tinha galinha, hoje em dia eu não tenho como criar galinha. Então, certas coisas assim que eu enquanto mãe queria que eles tivesse, esse tipo de experiência enquanto crianças eu vejo que porque a gente veio para cá (cidade) cortou um pouco isso. Perderam isso. Andar no mato com o pai. (...) Então, realmente nesse sentido de coisas que se aprende estando também no lugar que é bem legal perde um pouco (moradora 05).

Acredita-se que o distanciamento das crianças dos seus núcleos familiares e comunitários pode comprometer outros processos educacionais que ocorrem intimamente dependentes da interação das pessoas com seus lugares, além de comprometer a construção e o desenvolvimento dos vínculos das crianças e jovens com o território, com a natureza e a formação da identidade caiçara.

\section{Educação enquanto justiça ambiental}

As situações de injustiça ambiental refletem o modo como se organizam as condições materiais e espaciais de produção e reprodução da sociedade capitalista, especificamente em como se distribuem no espaço as distintas e desiguais formas de uso e apropriação dos recursos ambientais (ACSELRAD, 2010). A injustiça ambiental, portanto, aparece na apropriação privatista do território e dos recursos naturais, na concentração dos benefícios usufruídos do meio ambiente e na exposição desigual da população aos custos ambientais do desenvolvimento econômico capitalista (ACSELRAD, 2004).

Considera-se, então, que as populações caiçaras de Paraty encontram-se em situação de injustiça ambiental, uma vez que seus territórios tradicionais são constantemente alvos de disputas, sejam com as classes dominantes, que dispõem de maior poder para acessar os meios legais de garantir seus empreendimentos e/ou propriedades particulares, sejam com o poder público que define as políticas públicas para a região de forma pouco participativa e 
tendo como plano de fundo, muitas vezes, o atendimento dos interesses das classes dominantes (ABIRACHED, 2011; MIGUELETO, 2011). Desta forma, sofrem pressões diversas para deixarem seus lugares de moradia e trabalho, perdendo assim o acesso à terra e aos recursos naturais. Cada vez mais, se encontram em regiões distantes e desconectadas dos seus territórios tradicionais.

Como contra ponto ao termo injustiça ambiental cunhou-se a noção de justiça ambiental, utilizada, principalmente, para constituir uma integração ente as lutas ambientais e sociais na busca pela superação da dinâmica ambiental de injustiça social (ACSELRAD et al., 2009). Por justiça ambiental entende-se o "tratamento justo e o envolvimento pleno dos grupos sociais, independentemente de sua origem ou renda, nas decisões sobre o acesso, a ocupação e o uso dos recursos ambientais em seus territórios" (Ibid., p.25).

A justiça ambiental exprime um movimento de ressignificação da questão ambiental, resultante de uma aproximação da temática do meio ambiente com dinâmicas sociopolíticas tradicionalmente envolvidas com a construção da justiça social. Nessa aproximação, a temática ambiental se incorporou no debate mais amplo de crítica e busca por alternativas ao modelo dominante de desenvolvimento, construindo pautas comuns entre entidades ambientalistas e movimentos populares do campo, os movimentos comunitários das periferias das cidades, os povos tradicionais, etc. (ACESELRAD, 2010).

Assim, em Paraty a luta pelo território tradicional perpassa pela garantia de direitos sociais e à implementação de políticas públicas que atendam de fato as necessidades desses grupos sociais.

O maior objetivo hoje é a permanência dos territórios. Isso ai é nossa bandeira mesmo. A defesa dos territórios tradicionais. Isso ai a gente vamos pra luta, levanta a bandeira mesmo. Agora, ter um território também e não tem educação? Então, isso foi um pouco da nossa discussão. Hoje a gente discute o território sustentável e saudável. Tá falando de educação, saúde, toda as coisas. A sustentabilidade disso tudo (Ticote).

A permanência do território, esse é o foco principal. Além disso, vem educação diferenciada, agroecologia, turismo de base comunitária. Porque é a forma que a gente vê de desenvolvimento sustentável que a gente pode trabalhar. (...) buscando uma forma diferente para lidar com 0 turismo, de lidar com a agricultura, de fazer uma agricultura diferente, ou de fazer uma escola diferente (Marcela). 
Existe a compreensão por parte daqueles que fazem a luta política pelo território tradicional de que esta luta se desdobra em outras. Não basta o acesso à terra, se não se puder garantir formas de produção dos modos de vida nesse território, formas estas que vêm sendo definidas a partir de categorias ambientais, como é possível identificar nas falas dos caiçaras que, assim como em outros movimentos e/ou grupos sociais (PORTOGONÇALVES, 2006; LOUREIRO et al., 2009; MARTINEZ-ALIER, 2011), incorporaram as questões ambientais como elemento identitário e estratégico em suas lutas.

Deste modo, as antigas lutas por direitos costumeiros às terras e ao território das populações tradicionais também se expressam, atualmente, através das lutas por justiça ambiental, uma vez que as políticas escolhidas e impostas para a região e os investimentos do capital em territórios tradicionais, como exposto anteriormente, interferem diretamente na possibilidade de acesso e uso dos elementos naturais. A necessária regularização dos territórios tradicionais articula, além da questão étnica e o próprio problema ambiental, o tema agrário, educacional e da saúde, pois não se trata somente de garantir a regularização da posse da terra, mas também, de favorecer a melhoria da qualidade de vida dessas populações (PAIXÃO, 2004). Diegues (1996, p.13) afirma que a falta de políticas para os povos tradicionais tem se constituído na política real para esses grupos, podendo ser considerada como uma estratégia para "vencer as populações tradicionais pelo cansaço e pela desesperança".

Diante da situação conflituosa já apresentada, que coloca os caiçaras em situação de dominação, defende-se que o oferecimento de uma educação comprometida com as lutas sociais desses povos, não é só um direito social respaldado por diversas legislações, mas também é uma questão de justiça ambiental, uma vez que a falta do oferecimento da educação escolar completa em seus territórios mantem os caiçaras em relações de subordinação e dominação, além de ser um fator importante de expulsão dos caiçaras de seus territórios.

Os caiçaras precisam fazer a árdua escolha entre se mudar para outras localidades com escola, abandonando seus territórios e práticas tradicionais ou 
permanecerem em suas comunidades de pertencimento e se manterem sem acesso a escolarização. As escolhas entre essas duas únicas opções que se apresentam para eles são feitas de acordo com as experiências, expectativas, necessidades, compreensão, visão de mundo, sonho, esperança, receio, medo e condições materiais de cada família. A escolha de muitos caiçaras por sair para estudar, seja definitivamente ou temporariamente, demonstra a importância dada aos estudos. Mas, ao saírem de seus lugares para outras regiões com escolas em busca desse direito negado "perdem o direito" de reivindicarem pelos seus territórios, enfraquecendo a luta dos povos tradicionais e fortalecendo a lógica dominante (SOUZA e LOUREIRO, 2015). Aqueles que não possuem condições materiais se mantêm no território tradicional, sem acesso a escolarização ou sem completar os estudos, esperando pela chegada da escola.

Os dados do relatório As desigualdades na escolarização no Brasil (BRASIL, 2011) apresentam as dificuldades de ampliar o acesso à educação básica e erradicar o analfabetismo no Brasil, principalmente, para as populações que se encontram no campo. Vargas (2012) traz a informação de que entre 2002 e 2009 mais de 24 mil escolas do campo foram fechadas. O site do Movimento Sem Terra (MST) ${ }^{12}$ denuncia que, somente em 2014, o número de escolas fechadas localizadas na zona rural foi de 4.084. Em Paraty, ao longo dos anos diversas escolas localizadas na zona rural também foram fechadas. Em 2004, existiam no município 44 escolas municipais e 4 escolas estaduais (MMA, 2004), ou seja, foram fechadas mais de dez escolas municipais e uma estadual desde então. Segundo o site ${ }^{13}$ do Data Escola Brasil do Instituto Nacional de Estudos e Pesquisas Educacionais Anísio Teixeira (INEP), constam como paralisadas 14 escolas municipais, todas em áreas rurais incluindo três na Península da Juatinga, e 2 escolas estaduais, ambas em terras indígenas.

O fechamento das escolas do campo violam direitos fundamentais, geram retrocesso social e esvaziamento da população rural (HAYAMA, 2016), tendo como finalidade "silenciar" esses grupos: "se em tempos pretéritos a opção era

\footnotetext{
${ }^{12}$ http://www.mst.org.br/2015/06/24/mais-de-4-mil-escolas-do-campo-fecham-suas-portas-em2014.html

- Acesso em novembro de 2016.

${ }^{13}$ http://www.dataescolabrasil.inep.gov.br/dataEscolaBrasil/ - Acesso em dezembro de 2016.
} 
por mantê-la quando muito sob precárias condições, o que se pretende agora é apagá-las da história e da memória das comunidades camponesas e de trabalhadores rurais" (VARGAS, 2012, p141).

Além da falta de escolas em algumas localidades, a cultura escolar que se tornou hegemônica na sociedade capitalista é a voltada para a área urbana e, por isso, toda a lógica para a aplicabilidade deste sistema no ambiente rural gera um processo que é descontextualizado e não leva em consideração as particularidades e as características sociais, ambientais e culturais da classe trabalhadora do campo. O oferecimento da educação escolar, quando chega até as comunidades caiçaras, se dá através de uma política que não contempla as necessidades desses povos, vindo a cumprir mera formalidade legal. Até mesmo nas comunidades que possuem escolas, os jovens precisam fazer escolhas entre estudar ou participar das atividades tradicionais com os familiares, uma vez que a organização da escola é a mesma da cidade, não levando em consideração as suas épocas produtivas de pesca, caça e roça no calendário escolar, como aponta as diretrizes da educação do campo. Sendo a escola uma obrigatoriedade e também uma necessidade, se sobrepõe aos processos educativos das práticas tradicionais comunitárias.

Tem muito jovem que trabalha com a pesca. Dependendo do horário essas coisas que, às vezes, eles vão na parte da manhã e só voltam na parte da tarde. Botar rede, então, que demora, tem que esperar o peixe vir. Ai se manter (na escola) é complicado (moradora 06).

Eles têm dificuldade porque também do horário. O cerco vai de manhã, na hora do almoço e de tarde. Ai, fora eles vão pra escola no horário da parte da manhã e ai já chega atrasado na escola porque do cerco. E dependendo do tanto de peixe que vai pegar no cerco demora mais ainda. Eu acho que eles têm muita dificuldade (moradora 07).

Muitos outros grupos de população do campo, como as populações tradicionais, cada vez mais, vêm relacionando a luta pelo território com o direito à educação. É o caso, por exemplo, dos caiçaras das comunidades de Barra do Ribeira, Cachoeira do Guilherme, Rio Verde, Barra do Uma e Grajaúna, localizadas no sul do estado de São Paulo que, desde a década de 1970, passou por diversos conflitos com a chegada da especulação imobiliária, de grileiros de terras, a ameaça de implantação de uma usina nuclear na região e a criação da Estação Ecológica da Juréia-Itatins, em 1986, que proibiu diversas atividades como a roça e a construção de casas. Essas ações somadas ao 
fechamento das escolas levaram a expulsão de muitos moradores de suas comunidades.

O fechamento de quase todas as escolas por conta de uma medida da Secretaria da Educação do Estado de São Paulo tomada durante o primeiro mandato do governo de Mario Covas (1995-1998). A medida determinava que as escolas no estado de São Paulo com menos de quinze alunos por turma fossem fechadas. Tratava-se de uma política extremamente prejudicial a núcleos populacionais reduzidos, concentrando o ensino nos centros urbanos de maior porte. (...) Assim, o corte de recursos financeiros para as pequenas escolas da Juréia fez com que várias delas encerrassem suas atividades. Como consequência, assistiu-se à evasão de várias famílias de suas comunidades para cidades vizinhas, onde seus filhos pudessem estudar (CASTRO et al., 2015, p.562).

Hoje a luta pelo território tradicionais dos caiçaras da Juréia, da mesma forma que dos povos tradicionais de Paraty, também se dá associada à luta pelo acesso à educação escolar e pelo reconhecimento de suas práticas tradicionais como processo educativo, devendo estar atrelada ao processo de escolarização. Assim, verifica-se um padrão, um mesmo mecanismo, que se reproduz em diferentes contextos. Apesar das particularidades de cada localidade, cada povo, agentes envolvidos e as formas e mecanismos com os quais se deram as expropriações, que fazem cada experiência, história e vivências desses povos singulares, existe uma universalidade entre elas: a expansão capitalista sobre os territórios tradicionais com a criação de diversos processos de expropriações.

Então, reconhecer a escola enquanto um direito tem sido uma das lutas fundamentais desses grupos, aliada à luta pela terra e território. "Para além de ocupar a terra, é preciso ocupar a escola, porque como a terra, a escola tem sido um direito negado" (SCHWENDLER, 2001, p.379). Além disso, a escola tem negado a história, a cultura, os saberes construídos na experiência social desses povos, depositando neles, conteúdos vazios, sem significado e relação com suas vidas ( $l$ bid.).

Em Paraty, as propostas pedagógicas hoje oferecidas nessas comunidades caiçaras estão atreladas aos interesses dos grupos dominantes ${ }^{14}$ que, historicamente, se apropriam dos territórios tradicionais e das áreas protegidas com finalidades mercadológicas e privatistas. $\mathrm{Na}$ prática, tal

\footnotetext{
${ }^{14}$ São diversas as parcerias do poder público municipal com ONGs e instituições das classes dominantes. Entre elas temos: a Fundação Roberto Marinho, Fundação Itaú Social, Instituto Alpargatas, Associação Cairuçu, Comunitas, etc.
} 
educação não cumpre o papel de socializar os conhecimentos produzidos historicamente, pois tem se dado de forma superficial e aligeirada, produzindo e reforçando a precarização da educação pública, e muito menos atende aos interesses $e$ as necessidades dos povos tradicionais em luta. Assim, a educação formal descontextualizada das relações sociais que acontecem no território tradicional, além de naturalizar as relações sociais capitalistas, pode estar contribuindo para o encantamento pela cultura que é externa e dominante, reforçando o quadro de desvalorização dos conhecimentos e o abandono das práticas tradicionais da cultura caiçara.

Por esta razão, acredita-se que a luta pelo território tradicional em Paraty, especialmente das comunidades caiçaras da Península da Juatinga, está intimamente relacionada à luta pelo oferecimento de políticas públicas, incluindo uma educação que contribua para o desenvolvimento de um pensamento crítico, da compreensão da realidade e dos mecanismos que promovem e reforçam as expropriações dos territórios tradicionais. Pois, resistir ao projeto hegemônico de sociedade significa adquirir conhecimentos necessários para qualificar e criar suas formas de luta, ressignificar seus conhecimentos e reforçar seus valores, cultura e tradição. Além disso, o oferecimento da educação escolar nos territórios tradicionais pode garantir a permanência das populações tradicionais caiçara em seu território e pode vir a permitir o retorno daqueles que saíram de seus lugares em busca desse direito negado, aumentando a chance de construir e desenvolver os vínculos das crianças e jovens caiçaras com o território, com a natureza e a formação da identidade caiçara.

\section{Considerações finais}

Historicamente a expulsão dos povos tradicionais caiçaras de seus territórios se deu de forma direta, impositiva e até violenta. Apesar desses mecanismos ainda estarem presentes, hoje predominantemente o processo acontece de forma mais sutil, através da negação de direitos e de políticas públicas escolhidas para a região. Cada vez menos são aqueles que conseguem resistir a todas as pressões e ficam nos territórios tradicionais. 
A expansão das relações sociais capitalistas sobre os territórios tradicionais trazem necessidades de se recriar, resistir e traçar novas estratégias. A demanda por escolarização é uma delas, uma vez que os saberes relacionados às práticas e modos de vida dos povos tradicionais não são reconhecidos dentro deste sistema, criando assim hierarquias e colocandoos em situação de subordinação. Assim, ações colocadas em conjunto por diversos agentes se complementam e reforçam as expropriações dos povos tradicionais. São diversas as formas utilizadas através da escola para contribuir para esse processo. Pode ser através da forma como a escola se organiza, seu tempo, sua forma precária e aligeirada ou o seu conteúdo urbano, industrial, capitalista, que promove a invisibilidade dos modos de vida tradicionais.

Assim, o acesso à educação escolar tem se apresentado como uma questão de justiça ambiental, uma vez que a possibilidade de acesso aos recursos naturais e a proteção ambiental estão vinculadas a poder estudar e permanecer no seu próprio território, bem como ter acesso a conhecimentos produzidos historicamente. Os processos educativos visando contribuir para a luta caiçara têm que tratar das disputas e dos diferentes sentidos que 0 território e o meio ambiente adquirem nos diferentes projetos de sociedade. No atual modelo hegemônico, os territórios e tudo que nele está inserido, incluindo as pessoas, são potenciais mercadorias com valor de troca e possíveis de serem expropriados e privatizados. Uma educação que venha contribuir para a transformação desta realidade, onde os caiçaras tenham a possibilidade de decidirem sobre os processos de ordenamento e gestão ambiental nos seus territórios e que de fato proporcione a apropriação dos conhecimentos necessários para continuarem resistindo e a lutando pelo território tradicional precisa estar comprometida em reafirmar as identidades políticas desses povos e em resgatar suas formas de se relacionar com a natureza, além de construir conhecimentos que ajudem a compreender as estruturas de classe e os mecanismos de dominação, expropriação e alienação no capitalismo.

\section{Referências}

ABIRACHED, C. F. A. Ordenamento Territorial e Áreas Protegidas: conflitos entre instrumentos e direitos de populações tradicionais de Ubatuba-Paraty. 2011. 178f. Dissertação (Mestrado em Desenvolvimento Sustentável) - Centro 
de Desenvolvimento Sustentável, Universidade de Brasília (UNB), Brasília, 2011.

ACSELRAD, H., 2010. Ambientalização das lutas sociais: o caso do movimento por justiça ambiental. Estudos avançados, 24 (68): 103 - 118.

As práticas espaciais e o campo dos conflitos ambientais. In: (org.). Conflitos ambientais no Brasil. Rio de Janeiro: Relume Dumará, 2004. p.13-35.

; MELO, C. C.; BEZERRA, G. N. O que é justiça ambiental. Rio de Janeiro: Garamond, 2009. 156p.

BRASIL. Presidência da República; Conselho de Desenvolvimento Econômico e Social (CDES). As desigualdades na escolarização no Brasil: relatório de observação nํ 4. 2ª̃ed. Brasília: Presidência da República - CDES, 2011. 58p.

Decreto no 7.352, de 4 de novembro de 2010. Dispõe sobre a Política de Educação do Campo e o Programa Nacional de Educação na Reforma Agrária - PRONERA. Disponível em: http://www.planalto.gov.br/ccivil_03/_ato2007-2010/2010/decreto/d7352.htm Acesso em setembro de 2013.

Lei $\mathrm{n}^{\circ}$ 10.836, de 9 de janeiro de 2004. Cria o Programa Bolsa Família e dá outras providências. Disponível em: http://www.planalto.gov.br/ccivil_03/_ato2004-2006/2004/Lei/L10.836.htm Acesso em agosto de 2014.

CASTRO, R. R.; REZENDE, R. S.; ALMEIDA, M. W. B. Caminhos fechados: coerção aos meios de vida como forma de expulsão dos caiçaras da Juréia. In: SOUZA FILHO, C.F.M.; JOCA, P.M.; OLIVEIRA, A.S.; MILÉ, B.A.P.; ARAÚJO, E.F.; Moreira, E.M.; QUINTANS, M.T.D. (orgs.). Direitos Territoriais de Povos e Comunidades Tradicionais em Situação de Conflitos Socioambientais. Brasília: IPDMS, 2015. p. 545-567.

CAVALIERI, L., 2003. A comunidade caiçara no processo de reclassificação da Reserva Ecológica da Juatinga. 2003. 383f. Dissertação 
(Mestrado em Geografia Humana) - Departamento de Geografia, Universidade de São Paulo (USP), São Paulo, 2003.

CRUZ, V. C. Povos e Comunidades Tradicionais. In: CALDART, R. S.; PEREIRA, S. B.; ALENTEJANO, P. e FRIGOTTO, G. (orgs.). Dicionário da Educação do Campo. Rio de Janeiro, São Paulo: Escola Politécnica de Saúde Joaquim Venâncio, Expressão Popular, 2012. p.596 - 602.

DIEGUES, A. C. Populações humanas em áreas naturais protegidas da mata atlântica. São Paulo, NUPAUB-USP, 1996 (a). 18p.

FEITOSA, A. C.; SILVA, I. M.. Conflitos por terra e repressão no campo na região da Costa Verde, Litoral Sul Fluminense. In: MEDEIROS, L. S. (coord.). Conflitos Por Terra e Repressão No Campo No Estado do Rio De Janeiro (1946-1988). RELATÓRIO FINAL. Rio de Janeiro: CPDA/UFRRJ, 2015. p.292393.

FIPERJ - Fundação Instituto de Pesca do Estado do Rio de Janeiro. Relatório anual 2015. Rio de Janeiro: FIPERJ, 2015. 174p. Disponível em: http://www.fiperj.rj.gov.br/fiperj_imagens/arquivos/revistarelatorios2015.pdf Avesso em maio de 2017.

FONTES, 2010. O Brasil e o capital-imperialismo: teoria e história. $2^{\mathrm{a}}$ ed. Rio de Janeiro: EPSJV/Editora UFRJ, 2010. 388p.

HARVEY, D. O enigma do capital: e as crises do capitalismo. São Paulo: Boitempo, 2011. 235p.

HAYAMA, A. T. Patrimônio cultural imaterial e educação escolar diferenciada. In: STANICH NETO, P. Direito das comunidades tradicionais caiçaras. São Paulo: Editora Café com Lei, 2016. p.133-153.

LOUREIRO, C.F.B., 2015. Educação ambiental e epistemologia crítica. Revista eletrônica do mestrado em educação ambiental, 32 (2): 159-176.

Sustentabilidade e Educação: um olha da ecologia política. São Paulo: Cortez, 2012. 129p. 
; BARBOSA, G. L., ZBOROWSKI, M. B. Os vários "ecologismos dos pobres" e as relações de dominação no campo ambiental. In: LOUREIRO, C. F. B., LAYRARGUES, P. P., CASTRO, R. S. de (orgs.). Repensar a educação ambiental: um olhar crítico. São Paulo: Cortez, 2009. p.81-118.

; FRANCO, J. B. Aspectos teóricos e metodológicos do círculo de cultura: uma possibilidade pedagógica e dialógica em Educação Ambiental. In: LOUREIRO, C.F.B.; FRANCO, J.B. (orgs.) Educação ambiental: dialogando com Paulo Freire. São Paulo: Editora Cortez, 2014. 155-180p.

; GARAJAU, J., 2016. Individuo social e formação humana: fundamentos ontológicos de uma educação ambiental crítica. Ambiente e educação, 21 (1): 41-58.

MARINHA/PREPOM-Aquaviários. Programa de Ensino Profissional Marítimo para Aquaviários. Marinha do Brasil, 2017. 142p.

MARTINEZ-ALIER, J. M. O ecologismo dos pobres. São Paulo: Contexto, 2011. 384p.

MARTINS, A. S.; PINA, L. D.; ÁVILA, L. A.; ALMEIDA, R. D., 2014. Intelectuais, educação escolar e hegemonia: análise das formulações empresariais sobre trabalho docente. Revista HISTEDBR, 60: 260-272.

MARX, K. O capital. Crítica da economia política. Livro I, vol. 2. 29ª ed. Rio de Janeiro: Civilização brasileira, 2015. 3570.

MENDONÇA, M. O. Territórios, deslocamentos, permanência e transformações: o caso dos caiçaras da Praia Grande da Cajaíba/Paraty, RJ. 2010. 121f. Dissertação (Mestrado em Ciência Ambiental), Universidade de São Paulo (USP), São Paulo, 2010.

MigueletO, D. C. R. A encruzilhada do desenvolvimento. 2011. $152 \mathrm{f}$. Tese (Doutorado em Ciências Sociais), Instituto de Ciências Humanas e Sociais, Universidade Federal Rural do Rio de Janeiro (UFRRJ), Rio de Janeiro, 2011. 
MMA. Ministério do Meio Ambiente. Plano de Manejo da APA de Cairuçu: Encarte II - Sócio-economia. Estudo solicitado à Fundação SOS Mata Atlântica. 2004. 224p. Disponível em: http://www.pagem.uerj.br/textos/175_2009/docs/plano\%20cairu\%E7u/encartes/ Encarte\%202\%20-\%20Caracteriza\%E7\%E30\%20Socio\%20Economica.pdf Acesso em novembro de 2016.

MONGE, R. P. M. "Nascido e criado": a ocupação tradicional da Família dos Remédios, uma comunidade "caiçara" - Península da Juatinga, município de Paraty/RJ. 2012. 176f. Dissertação (Mestrado em Ciência Ambiental) - Instituto de Geociências, Universidade Federal Fluminense (UFF), Niterói, 2012.

NOBRE, D. B. Todo índio na escola. Parte I: infância indígena e escolarização no Brasil (1999-2009). Campinas: Curt Nimuendaju, 2016. 712p.

PAIXÃO, M. O verde e o negro: a justiça ambiental e a questão racial no Brasil. In: ACSELRAD, H.; HERCULANO, S.; PÁDUA, J. A. (orgs.). Justiça ambiental e cidadania. $2^{\underline{a}}$ ed. Rio de Janeiro: Relume Dumará; Fundação Ford, 2004. p.159-168.

PORTO-GONÇALVES, C. W. A globalização da natureza e a natureza da globalização. Rio de Janeiro: Civilização brasileira, 2006. 461p.

SAVIANI, D., 2014. A pedagogia histórico-crítica. Revista binacional BrasilArgentina, 3(2): 11-36.

. Pedagogia histórico-crítica: primeiras aproximações. $11^{\mathrm{a} e d}$. Campinas: Autores Associados, 2011. 137p.

SCHWENDLER, S. F. A pedagogia de Paulo Freire inserida no contexto dos movimentos sociais. In: Anais do III Colóquis Internacionais Paulo Freire: Pedagogia e Reinvenção da Sociedade. Recife: Editora UFPB, 2001. p. 376383.

SIQUEIRA, P. Genocídio dos caiçaras. São Paulo: Massao Ohno, Ismael Guarnel editores, 1984. 92p. 
SOUZA, V. M.“Educação para permanecer no território”: a luta dos povos tradicionais caiçaras da Península da Juatinga frente à expansão do capital em Paraty-RJ. 2017. 384f. Tese (doutorado em Psicossociologia de Comunidades e Ecologia Social) - Universidade Federal do Rio de Janeiro (UFRJ), Rio de Janeiro, 2017.

; LOUREIRO, C.F.B., 2015. A educação formal enquanto estratégia de luta dos povos caiçaras da Península da Juatinga, Paraty/RJ. Revista cadernos de educação, 51: 1-21.

VARGAS, L. A. A. Por uma pedagogia da luta e da resistência: a educação como estratégia política no MST. 2012. 293f. Tese (Doutorado em Educação) Faculdade de Educação, Universidade Federal do Rio de Janeiro (UFRJ), Rio de Janeiro, 2012. 